\title{
Interactions between chloride and cement-paste materials
}

\author{
Fabien Barberon ${ }^{\mathrm{a}, \mathrm{b}, *}$, Véronique Baroghel-Bouny ${ }^{\mathrm{a}}$, Hélène Zanni ${ }^{\mathrm{b}}$, Bruno Bresson ${ }^{\mathrm{c}}$, \\ Jean-Baptiste d'Espinose de la Caillerie ${ }^{c}$, Lucie Malosse ${ }^{b}$, Zehong Gan ${ }^{d}$ \\ ${ }^{a}$ Laboratoire Central des Ponts et Chaussées, 75732 Paris cedex 15, France \\ ${ }^{\mathrm{b}}$ Laboratoire de Physique et Mécanique des Milieux Hétérogène, UMR 7636, ESPCI, 10 rue Vauquelin, 75231 Paris cedex 05, France \\ ${ }^{\mathrm{c}}$ Laboratoire de Physique Quantique, UMR 7142, ESPCI, 10 rue Vauquelin, 75231 Paris cedex 05, France \\ ${ }^{\mathrm{d}}$ National High Magnetic Field Laboratory, 1800 East Paul Dirac Drive, Tallahassee, FL 32310, USA
}

\begin{abstract}
The durability of cement-based materials with respect to exterior aggressions is one of the current priorities in civil engineering. Depending on their use, the cement-based materials can be exposed to different types of aggressive environments. For instance, damages to concrete structures in contact with a saline environment (sea water on bridges, deicing salts on roads, etc.) are of utmost importance. Upon exposure to saline water, $\mathrm{Cl}^{-}$ions penetrate into the structures and subsequently lead to reinforcement corrosion. Chloride attack is often combined with other aggressive influences such as temperature (e.g., freezing) or the ingress of other ions (e.g., sulfates in sea water). We therefore aim to explore the effect of sodium chloride $(\mathrm{NaCl})$ on the structural chemistry of cement paste.

Existing studies about reinforcement corrosion by chloride have focused on the penetration of $\mathrm{Cl}^{-}$ions and the comparison between "free" ions (water-soluble ions) and bound ones. However, little is known about the fixation mechanisms, the localization of $\mathrm{Cl}$ in the cement matrix and the structural interaction between $\mathrm{Cl}$ and the silicate and aluminate hydrate phases present in cement paste. We present here results of a multinuclear nuclear magnetic resonance study on the fixation of chloride in the hydration products and the characterization of new phases potentially appearing due to chloride ingress.
\end{abstract}

(C) 2005 Elsevier Inc. All rights reserved.

Keywords: Chloride; Cement paste; Concrete; Nuclear magnetic resonance; Nuclear magnetic relaxation

\section{Introduction}

A quantitative approach to durability is necessary to predict the long-term behavior of concrete structures. Corrosion of steel reinforcement is the major problem when no mechanical solicitations or chemical reactions occur. While sulfates or carbonates can also lead to the deterioration of concrete, chloride is probably the most aggressive and most widespread corrosive ion. It is therefore essential to understand the interactions between chloride and concrete in order to identify and predict all the mechanisms involved. When concrete is in contact with a chloride solution, chloride ions penetrate in the pore solution. They appear in concrete both as "free" $\mathrm{Cl}^{-}$ions (meaning water-soluble ions) in the pore interstitial solution and as chemically bound component of hydrate phases (e.g., Friedel's salt $\mathrm{Ca}_{2} \mathrm{Al}(\mathrm{OH})_{6} \mathrm{Cl} \cdot 2 \mathrm{H}_{2} \mathrm{O}$ [1]). Free chloride ions are the most dangerous because of their capacity to diffuse towards the steel bars [2].

Interactions between chloride and concrete can be explored by different ways. Studies on the kinetics of chloride ingress by natural diffusion, migration under an electrical field or microstructural characterization are usual methods [3,4]. In this paper we propose to explore these interactions by using nuclear magnetic resonance (NMR). Nuclear magnetic resonance is well known to the study of the microstructure of cement-paste materials. Concerning the binding of chloride, few works exist and most of them are ${ }^{27} \mathrm{Al}$ studies [5]. The lack of ${ }^{35} \mathrm{Cl} \mathrm{NMR}$ reference studies [6-8] is an obstacle for the comprehension of chloride binding in concrete.

A two-step approach is conducted here to study the interactions between chloride and cement-paste hydrates. First, the modifications of the hydration kinetics in 
presence of chloride are determined by the evolution of both the longitudinal relaxation rate $\left(1 / T_{1}\right)$ and the NMR-detectable amount of chloride with hydration time are explored. And on the other hand, ${ }^{29} \mathrm{Si},{ }^{27} \mathrm{Al}$ and ${ }^{35} \mathrm{Cl}$ NMR spectra of hardened materials are presented in order to identify possible modifications of the microstructure. These spectra were obtained on different Bruker spectrometers operating with field of $2.85,7.0,11.7$ and $19.6 \mathrm{~T}$.

\section{Modifications of the hydration kinetics}

The intrusion of chloride in a cement-paste material usually results from the contact with a saline solution. In the experiments presented here, the presence of chloride was achieved by direct addition of chloride to the pastes. The ratio (mass of $\mathrm{NaCl}$ )/(mass of cement) is $3 \%$ and the water/ cement $(\mathrm{w} / \mathrm{c})$ ratio is 0.35 in all the tested materials. The freshly prepared pastes were put into $8-\mathrm{mm}$-diameter $1-\mathrm{cm}$ length static tubes for the $T_{1}$ longitudinal relaxation time and spectral measurements realized at different hydration times. We tested three different materials: two cement pastes named HTS and Le Havre containing 4\% and $10 \%$ of $\mathrm{C}_{3} \mathrm{~A}$ (calcium aluminate: $3 \mathrm{CaO} \cdot \mathrm{Al}_{2} \mathrm{O}_{3}$ ), respectively (the rest of the chemical composition is the same), and a pure $\mathrm{C}_{3} \mathrm{~S}$ paste (calcium silicate: $3 \mathrm{CaO} \cdot \mathrm{SiO}_{2}$ ).

In Fig. 1, ${ }^{23} \mathrm{Na} \mathrm{NMR}$ spectra measurements measured at $2.85 \mathrm{~T}$ on a HTS cement paste are presented. The longitudinal relaxation rate $1 / T_{1}$ and the detectable sodium amount evolve in three steps:
- Until a hydration time of $200 \mathrm{~min}$, both the amount of detectable sodium and the relaxation rate are constant; the observed relaxation behavior in this time interval is monoexponential.

- From 200 to $\sim 10000 \mathrm{~min}$ ( $\sim 7$ days), the relaxation rate is divided in two components; one is attributed to the bulk $\mathrm{Na}^{+}$ions (from 500 to $2500 \mathrm{~s}^{-1}$ ) and the other one to the $\mathrm{Na}^{+}$ions at the surface of the material (from 500 to $30000 \mathrm{~s}^{-1}$ ). During this 5-day period, the amount of detectable sodium decreases from $100 \%$ to $\sim 20 \%$.

- After 7 days, both relaxation rate and amount of detectable sodium are roughly constant.

This result suggests that there is no specific interaction between the sodium ion and the hydrating cement. The decrease in the amount of detectable sodium is due to its confinement in progressively smaller pores during the course of the hydration process.

In a second experiment, the kinetics of the hydration process was studied by ${ }^{35} \mathrm{Cl} \mathrm{NMR}$. A comparison of the results obtained for the cement pastes (the curves for HTS and Le Havre were obtained at 2.85 and $7 \mathrm{~T}$, respectively) and a $\mathrm{C}_{3} \mathrm{~S}$ paste (measured at $2.85 \mathrm{~T}$ ) is given in Fig. 2. The kinetics for the HTS cement and $\mathrm{C}_{3} \mathrm{~S}$ cement is quite similar and three periods can be identified:

- Until $250 \mathrm{~min}$, the amount of detectable chloride and the relaxation rate are constant.

- From 250 to $\sim 500 \mathrm{~min}(\sim 8 \mathrm{~h})$, only one relaxation rate is obtained varying from 60 to $600 \mathrm{~s}^{-1}$. This

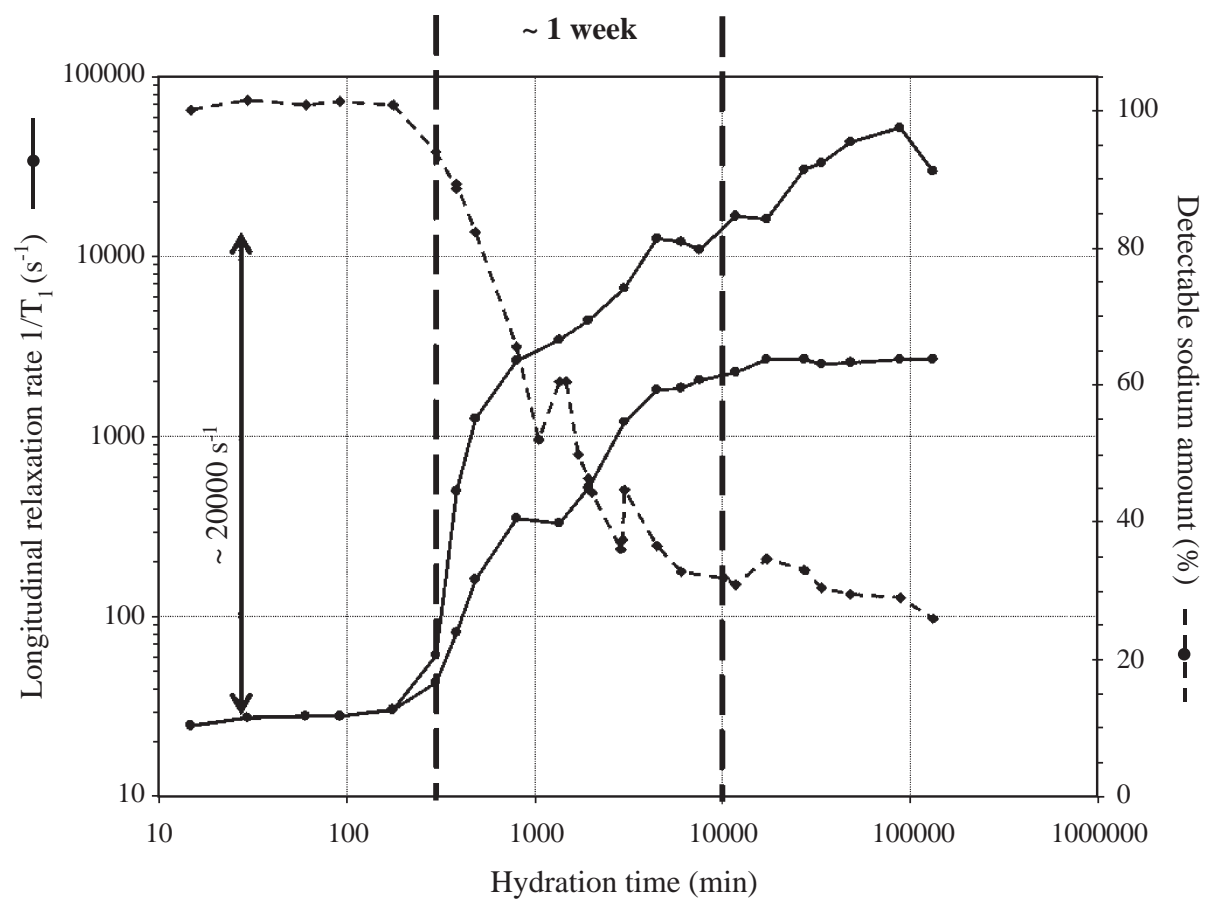

Fig. $1 .{ }^{23} \mathrm{Na}$ kinetics of hydration for a cement paste $(\mathrm{w} / \mathrm{c}=0.35)$ with an addition of $3 \% \mathrm{NaCl}$ in mass of cement. After the onset of the hydration process, two relaxation rates are observed: one can be attributed to the $\mathrm{Na}^{+}$ions in the pore volume and the other to the $\mathrm{Na}^{+}$ions adsorbed at the surface of the material. The decrease of the amount of detectable sodium is due to its confinement into smaller and smaller pores over the course of the hydration process. 
for HTS) and especially the increase of the relaxation rate $1 / T_{1}$ is much higher (1300 $\mathrm{s}^{-1}$ for Le Havre instead of $500 \mathrm{~s}^{-1}$ for HTS).

In order to gain further insights into the interactions between chloride and the cement matrix, high field spectra are realized on cement paste as well as on older concrete.

\section{Spectroscopic studies on the effect of chloride exposure}

Two kinds of materials have been studied. The first one was a 28-day-aged HTS cement paste with a ratio $\mathrm{w} / \mathrm{c}=0.35$ and hydrated directly with a solution containing $3 \%$ of $\mathrm{NaCl}$ in mass of cement. The other material was an ordinary concrete (named BO) obtained by mixing sand, aggregates and the same cement as in the paste with a ratio $\mathrm{w} / \mathrm{c}=0.5$. After 213 days of hydration and vacuum water diffusion, a 10 -cm-height 11-cm-diameter cylinder of this concrete was put in contact for 61 days with a basic solution of $\mathrm{NaCl}$ / $\mathrm{NaOH}$ (30 and $4 \mathrm{~g} / \mathrm{L}$, respectively) to match the $\mathrm{pH}$ of the interstitial solution of the material. Finally, the concrete cylinder was stored at ambient conditions for several weeks.

Different nuclei were studied to explore the possible interactions between chloride and the material.

\section{1. ${ }^{29}$ Si MAS NMR}

${ }^{29} \mathrm{Si}$ experiments at $11.7 \mathrm{~T}$ have been performed on samples of the $\mathrm{BO}$ concrete non-altered and altered by the $\mathrm{NaCl} / \mathrm{NaOH}$ solution. The resulting spectra for the concrete samples as well as for the cement paste are shown in Fig. 3. One observes that the $Q_{0}$ contribution for the chlorideexposed sample decreases whereas the $Q_{1}$ and $Q_{2}$ ones increase. From these quantitative spectra, the mean length $l$ of tetrahedral chains can be determined $\left(l=Q_{2} / Q_{1}\right)$ as well as the mean percentage of hydration phases $\left(C_{\text {hyd }}=Q_{1}+Q_{2}\right)$. For the reference sample, we obtain $l=0.77$ and $C_{\text {hyd }}=87 \%$, and for the chloride-exposed sample $l=0.76$ and $C_{\text {hyd }}=94 \%$. Moreover, the decrease of $Q_{0}$ contribution is about $10 \%$. Concerning the cement paste, the spectrum is dominated by a large contribution $Q_{0}$ of nonhydrated cement $\left(C_{\mathrm{hyd}}=69 \%\right)$ and a more prominent contribution of $Q_{1}$ respect to $Q_{2}(l=0.65)$.

The length of the siliceous chains is not notably affected by the chloride exposure. The main effect of the treatment with saline solution is therefore the hydration of unhydrated cement still present in concrete.

\section{2. ${ }^{27}$ Al MAS NMR}

The same kind of comparison has been made for the ${ }^{27} \mathrm{Al}$ nucleus. The results, including the cement paste spectrum, are shown on Fig. 4. The BO concrete spectra were recorded at $11.7 \mathrm{~T}$ whereas the cement paste was measured at 19.6 T. Two contributions can be observed. Between -10 and $25 \mathrm{ppm}$, the octahedral group corresponds to the aluminate hydrates; its main components are AFm (monosulfoaluminate), AFt (trisulfoaluminate) and (in the chloride-exposed samples) Friedel's salt [5] as well as a peak due to hydration (aluminum in octahedral position instead of calcium). The signal due to tetrahedral groups observed between 50 and $100 \mathrm{ppm}$ corresponds to aluminum incorporated into the $\mathrm{C}-\mathrm{S}-\mathrm{H}$ or to $\mathrm{Al}$ contained in still unhydrated cement.

Three effects are observed upon contact with the saline solution. First, the increased amount of hydrates indicates
A1 VI

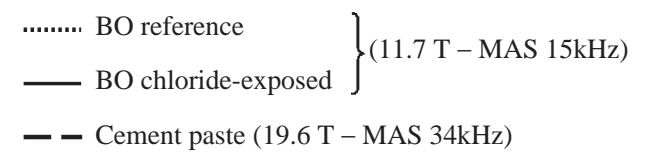

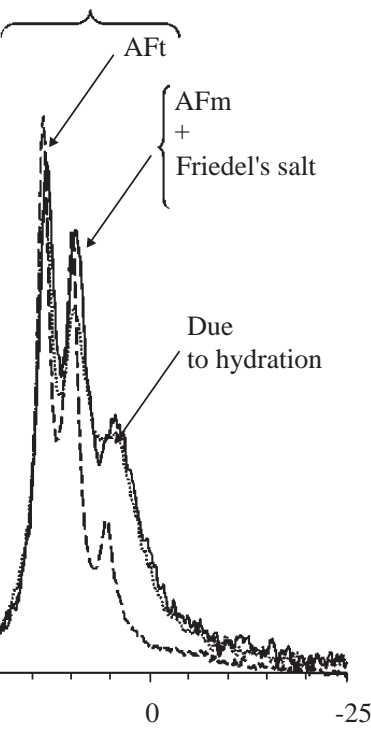

Fig. $4 .{ }^{27} \mathrm{Al}$ spectra of the concrete $\mathrm{BO}$ reference sample (dotted line) and the chloride-exposed sample (full line) at $11.7 \mathrm{~T}$ and the ${ }^{27} \mathrm{Al}$ spectrum of the cement paste (dash line) at 19.6 T. Exposure to chloride leads to the formation of Friedel's salt. Al IV modifications appear when the concrete is in contact with a saline solution. Al IV for the cement present only the characteristic of aluminum incorporated in the cement. 
Variable temperature ${ }^{35} \mathrm{Cl}$ NMR spectroscopy of hydrotalcite and Caaluminate hydrate (hydrocalumite). Am Mineral 1999;84:1186-90.

[7] Kalinichev AG, Kirpatrick RJ, Cygan RT. Molecular modeling of the structure and dynamics of the interlayer and surface species of mixedmetal layered hydroxides: chloride and water in hydrocalumite (Friedel's salt). Am Miner 2000;85:1046-52.
[8] Yun H, Patton ME, Garret JH, Fedder GK, Frederick KM, Hsu J-J, et al. Detection of free chloride in concrete by NMR. Cem Conc Res 2004;34:379-90.

[9] Plassais A. PhD thesis, Universite Pierre et Marie Curie, 2003.

[10] Le Saoût G, Lécolier E, Riverau A, Zanni H. Study of oilwell cements by solid-state NMR. C R Chimie 2004;7:383-8. 